dikirim: 10 Agustus 2015 diterbitkan: 1 Februari 2016

\section{Clinical learning experiences and professional development: implementation of a district level undergraduate midwifery program in Indonesia}

\author{
Eva Rusdianah ${ }^{1}$, Mubasysyir Hasanbasri $^{2}$, Mohammad Hakimi $^{2}$
}

\begin{abstract}
Purpose: The aim is to examine the suitability of the educational process in place with the expected professional development. Method: We conducted in-depth interviews with (a) 16 third-year student who recently completed 2-month clinical rotation in the hospital and (b) four teachers. Results: Evidence from this study indicate weak learning environment. Clinical instructor only has a limited time to meet with students, so that students rarely get the guidance and direct supervision. Students more often obtain "lessons" of the young staff, which many of them indifferent in providing guidance. Students feel insecure and fear in communicating with senior staff from both the nursing and medical professions. Academic lecturers provide minimum learning support. Their supervision does not allow students to reflect on their experiences. Conclusion: Professional development as reflected in clinical rotations in hospitals is still very limited. The government must monitor more strictly, especially for the medical school located in the district, where professional educators are very limited.
\end{abstract}

Keywords: midwifery training; hospital based learning; learning environment; low resource setting

\footnotetext{
${ }^{1}$ Department of Health Policy and Management, Faculty of Medicine, Universitas Gadjah Mada (Email: evadianah@gmail.com) ${ }^{2}$ Department of Biostatistics, Epidemiology and Population Health, Faculty of Medicine, Universitas Gadjah Mada
} 


\section{INTRODUCTION}

There is a growing market for midwives due to government policy to deploy midwives for reducing maternal mortality (1). Private college of midwives have spread throughout the country, even in small towns in the last decade. This phenomenon raises a question on whether it is truly for education or for money (2). This study comes as concerns about the potential failure of development of the health system in response to stagnant maternal mortality problems in Indonesia. On the one hand, we do not worry if our effort to improve health system ends with creating commercialization of education. On the other hand, if training institutions fail to produce professional midwives, Indonesia will not be free from chronic problem of maternal mortality. This study aims to show the weakness of the educational process in the context of public health issues and the political economy of education. We try to portray learning practices in hospital from a humanistic approach to teaching and learning.

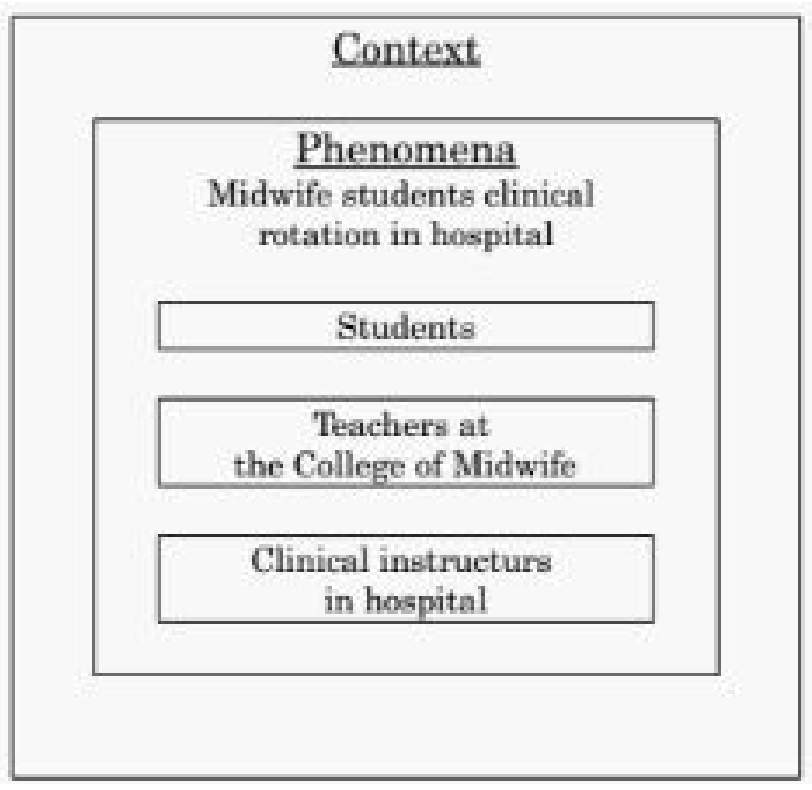

Figure 1. Definition of single case study

\section{METHOD}

We use a single design case study (3). Our research focuses on learning activities in developing professional behavior in pre-service training. We interviewed 4 clinical supervisors and 16 third year students on their experiences during the two-month clinical rotation in a small private hospital in the City of Madiun in East Java.

\section{FINDINGS}

Poor learning environment during hospital clinical rotation. Clinical rotation is meant to give students the opportunity to gain first-hand observation on midwifery professional practices (4). Students can also follow the activities directly under the supervision of hospital staff (5). In their clinical rotation, students feel the work climate at the hospital. They interact with patients, colleagues midwives, doctors, administrative staff and other professions are also supportive. More importantly, students can ask questions and talk to the hospital staff appointed by hospital administrator as clinical Instructor $(6,7)$. Our study shows that hospital staff do not understand that clinical rotation is a place where students learn about the real practices of their profession. They are just everyday greatest role for students. They give students the opportunity to see first hand the activities and explain their work. They do not offer explanations and discussions to students. Without explaining the standards and what students do in practice, all things "not true" that the staff do in hospitals are considered as professionally correct by students. Midwifery teacher should test students' progresses. They are responsible for reviewing what happened in the hospital clinical rotation. By understanding those that cannot be achieved from the learning process in the hospital, they could think of other better learning strategies. They should listen what students learn and what are the gaps between their knowledge and the practices. Unfortunately, they do not do this job by themselves. They handed over entirely to the clinical evaluation instructor in collaborating hospitals. This has an impact on teachers having no information about student competencies.

\section{Fundamental weaknesses in learning process that should receive significant attention \\ - Colege administrators employ health workers in the hospital who ore not troined es educotors. \\ - Learning activities do not support the development of professional behaviors of midwives. \\ - Learning activifies keep students away from humanistic values that they should be part of their chcrocter}

\section{CONCLUSION}

This study is the result of applying a critical approach to health professions education in the context of maternal mortality problems. For Indonesia, education of health profession is a strong indicator of whether the Indonesian health system has progressed. This small study should serve as impetus for other 
researchers to show evidence of profit-making in midwifery education, which is detrimental to the health system. Other studies would show weak implementation of government regulation and supervision to health profession education production. Such studies should open the eyes of policy makers so that they can take actions to prevent from deterioration of health system.

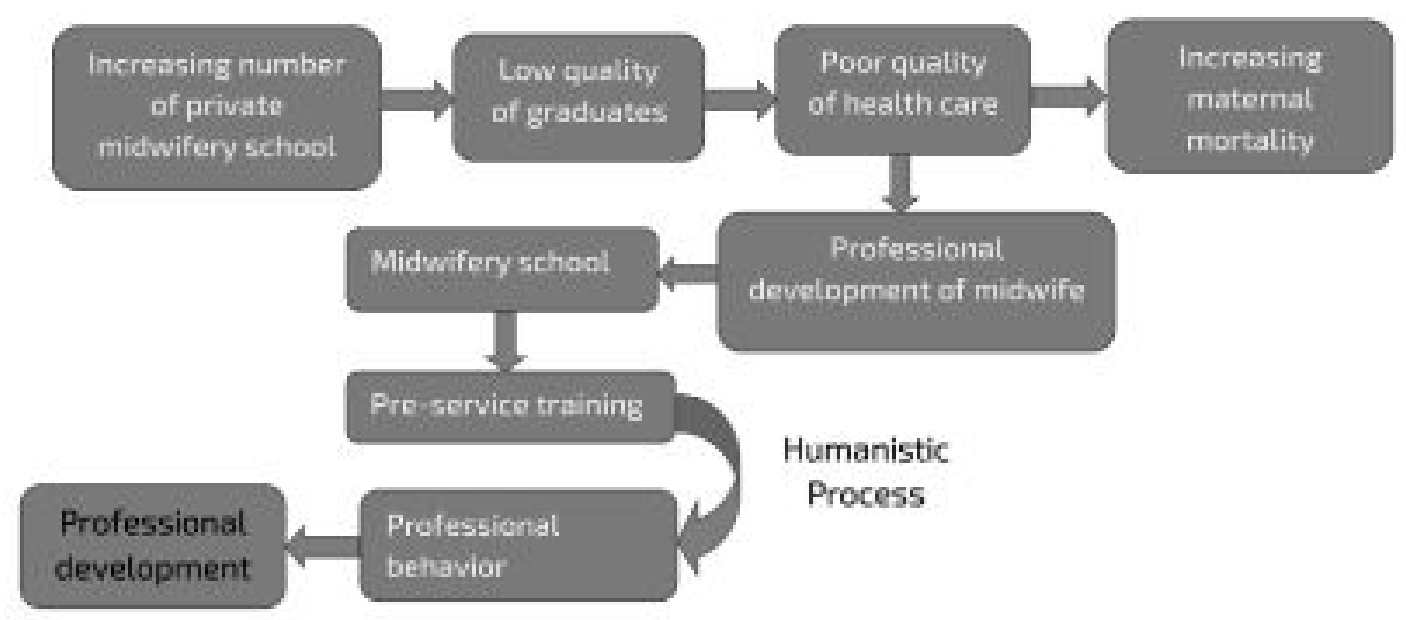

Figure 2. The framework of reserach

\section{REFERENCES}

1. Stern DT, Frohna AZ, Gruppen LD. The prediction of professional behaviour. Medical Education. 2005 Jan 1;39(1):75-82.

2. Decker JL, Shellenbarger T. Strategies for nursing faculty to promote a healthy work environment for nursing students. Teaching and Learning in Nursing. 2012 Apr 1;7(2):56-61.

3. Yin RK. Enhancing the quality of case studies in health services research. Health services research. 1999 Dec;34(5 Pt 2):1209.

4. Bourgeois, S., Drayton, N., \& Brown, A. (2011). An innovative model of supportive clinical teaching and learning for undergraduate nursing students:
The cluster model. Nurse Education in Practice, 11(2), 114-118.

5. Cusick A, Heydon M, Caldwell K, Cohen L. Finding measures of clinical placements quality for pre-service health services training: challenges of definition and search strategy construction.

6. Gray J, Leap N, Sheehy A, Homer CS. Students' perceptions of the follow-through experience in 3 year bachelor of midwifery programmes in Australia. Midwifery. 2013 Apr 1;29(4):400-6.

7. O'Mara L, McDonald J, Gillespie M, Brown H, Miles L. Challenging clinical learning environments: Experiences of undergraduate nursing students. Nurse education in practice. 2014 Mar 1;14(2):208-13.

Notes:

The paper is based on a poster presented in the 9th Postgraduate Forum on Health Systems and Policies 2015 Provider Payment Reforms in South East Asia: Impact and Lessons Learned 14-15th September 2015. The abstract has been published in the proceeding.

(https://www.mjphm.org.my/mjphm/journals/2015\%20-\%20Volume\%2015\%20(Sup\%201)/9th\%20postgraduate\%20fo rum.pdf) 
Berita Kedokteran Masyarakat, Volume 32 No. 2 Tahun 2016 